\section{Prognostic implications of vitamin D deficiency in chronic kidney disease}

\author{
D Martínez-López¹, D Jover-Ríos², P Esteve-Atiénzar³ , J Méndez- \\ Mora ${ }^{4}$, A Méndez-Jover ${ }^{4}$, F Caparrós-Hernández ${ }^{4}$, V Jordá- \\ Climent ${ }^{4}$, C Seguí-Pérez ${ }^{4}$, M Seguí-Pérez ${ }^{4}$, C García-Cervera ${ }^{3}$, \\ JM Núñez-Cruz ${ }^{3}$, J Guzmán-Martínez ${ }^{3}$, I Hernández-Isasi ${ }^{3}$, D \\ Bonet-Tur ${ }^{3}$, S Bañón-Escandell ${ }^{3}$, J Peris-García ${ }^{3,5}$, P Roig-Rico ${ }^{3,5}$, \\ A Pérez-Fullana ${ }^{4}$ and JM Seguí-Ripoll ${ }^{3,5 *}$

\begin{abstract}
${ }^{1}$ Miguel Hernández University, School of Medicine, Elche (Alicante), Spain ${ }^{2}$ Department of Internal Medicine, Hospital La Vega Baja of Orihuela (Alicante), Spain ${ }^{3}$ Department of Internal Medicine, University Hospital of San Juan, Alicante, Spain ${ }^{4}$ Secondary School, Marist Brothers High School, Alicante, Spain
\end{abstract} \\ ${ }^{5}$ Department of Clinical Medicine, Miguel Hernández University, Elche (Alicante), Spain
}

\section{Abstract}

Chronic kidney disease (CKD) is a highly prevalent disease, imposing high mortality rates worldwide, and it is closely related to cardiovascular events. Vitamin D deficiency is very prevalent in patients with CKD from the earliest stages of the disease, and it has been associated with higher mortality. In order to assess the prognostic implications of vitamin D deficiency in CKD, we undertook a literature review, searching different databases in October 2018 for publications related to vitamin $D$ in patients with CKD and hypovitaminosis $D$, and not on dialysis. The main cause of death in these patients is cardiovascular disease. Vitamin $D$ is one of the first parameters that CKD changes and has an important prognostic role in this entity. Deficient levels in blood are associated with increased cardiovascular risk and survival impacts, independently of cardiovascular disease. Treatment with paricalcitol appears to reduce this risk. However, the evidence analyzed is insufficient to establish an association between vitamin D levels and the progression of kidney disease.

\section{More Information}

*Address for Correspondence: Dr. JM SeguíRipoll, Department of Internal Medicine, University Hospital of San Juan, Alicante, Spain, Department of Clinical Medicine, Miguel Hernández University (UMH), Elche, Spain, Tel: +34965938878. Fax: +34965938652; Email: jsegui@umh.es

\section{Submitted: 25 July 2019 \\ Approved: 06 August 2019 \\ Published: 07 August 2019}

How to cite this article: Martínez-López D, Jover-Ríos D, Esteve-Atiénzar P, Méndez-Mora J, Seguí- Ripoll JM, et al. Prognostic implications of vitamin D deficiency in chronic kidney disease. J Clini Nephrol. 2019; 3: 148-153.

DOI: 10.29328/journal.jcn. 1001040

Copyright: () 2019 Martínez-López D, et al. This is an open access article distributed under the Creative Commons Attribution License, which permits unrestricted use, distribution, and reproduction in any medium, provided the original work is properly cited

Keywords: Vitamin D deficiency; Chronic kidney disease; Mortality; Cardiovascular disease; Prognosis

Abbreviations: CKD: Chronic Kidney Disease; VDR: Vitamin D Receptor; 25(OH)D3 (25-hydroxyvitamin D3): Calcifediol 1,25- $(\mathrm{OH}) 2$ D3 (1,25-dihydroxyvitamin D3) or 1,25 Vit D: Calcitriol; PTH: Parathyroid Hormone; FGF23: Fibroblast Growth Factor 23; GFR: Glomerular Filtration Rate

Check for updates

\section{Introduction}

Chronic kidney disease (CKD) affects a considerable proportion of the world population, especially the elderly. The World Health Organization (WHO) estimated that in 2012, more than 800,000 deaths were attributable to this entity, representing $1.5 \%$ of global mortality, $1.1 \%(2,968,000)$ of disability adjusted life years (DALYs) lost and 1.3\% $(2,546,700)$ years of potential lost life (YPLLs) worldwide [1]. CKD ranks as the $14^{\text {th }}$ cause of death globally at a rate of 12.2 deaths per 100,000 population. In Spain, the prevalence of stage 3 and 4 CKD is $6.8 \%$ in the general population, and $21.42 \%$ in people aged 65 or older, constituting a public health problem of great impact [2].

Vitamin D, for its part, is a hormone with clearly established effects in the mineral and bone metabolism; however, recent studies are revealing novel pleiotropic effects as a result of the activation of the vitamin $\mathrm{D}$ receptor (VDR) in different tissues. These discoveries could lead to a revolution in the management of vitamin $D$ in several pathologies to which it is related. In addition to its association with musculoskeletal diseases like rickets and osteomalacia, vitamin D deficiency has been linked with chronic diseases like chronic pulmonary obstructive disease (COPD) and hypertrophic cardiopathy [3]. Hypovitaminosis D is highly prevalent in patients with CKD from the earliest stages of the disease, but it also seems to be very common at subclinical levels in the general population, with an uncertain significance.

We undertook a literature review to assess data on cardiovascular events and the potential prognostic implications of vitamin D deficiency in patients with stage 3 and 4 CKD. 


\section{Material and Methods}

We included original articles, reviews, clinical trials, and meta-analyses of trials with the primary objective of assessing the prognostic implications of vitamin D deficiency in adults with CKD. Primary outcomes were mortality and cardiovascular events.

\section{Search strategy}

We searched Google Scholar, MEDLINE and UpToDate for documents and clinical practice guidelines published by different societies and professional associations, both in Spain and internationally, on CKD and on vitamin D (epidemiology of hypovitaminosis and its physiological effects). Secondly, we performed a search for records relating the two entities, focusing on both the prevalence of vitamin D deficiency in these patients and the prognostic implications of vitamin D in CKD. We narratively reviewed the papers of the most importance or which presented the best evidence in relation to the primary objective of the review, as judged by the first author. The search period was limited to the most recent 10 years, with the search beginning in October 2008. We reviewed the bibliographies of included papers to verify the basis of their conclusions, identify further related papers, and draw our own conclusions about the body of evidence. A total of 26 manuscripts were choosen.

Table 1 shows the search terms used during the MEDLINE search. In Google Scholar, we ran different searches with terms like "Cardiovascular events in patients CKD 25(OH)D Vitamin D," "Vitamin D mortality CKD adults," "Pleiotropic effects vitamin D VDR," and "Progression Chronic Kidney Disease Vitamin D levels". In UpToDate, the current reviews were analyzed on: "Vitamin D deficiency in adults", "Overview of chronic kidney disease-mineral and bone disorder" and "Vitamin D and extraskeletal health".

\section{Data analysis}

The results of the literature review were structured into two subsections: first, on aspects related to the synthesis and metabolism of vitamin D, its pleiotropic effects, and the role of vitamin D deficiency in the general population; and second, the studies relating hypovitaminosis D with CKD, from its pathogenesis to the prognostic implications in this pathology.

\section{Results}

\section{Vitamin D}

Synthesis and metabolism of vitamin D: The main

\begin{tabular}{|c|c|}
\hline Table 1: MEDLINE search terms on chronic kidney disease and vitamin D deficiency. \\
\hline \multicolumn{2}{|c|}{ MEDLINE (Medical Subject Headings) } \\
\hline "Calcifediol/deficiency" & "Renal insufficiency, Chronic" \\
\hline "Cardiovascular Diseases" & "Renal Insufficiency, Chronic/mortality" \\
\hline "Prognosis" & "Vitamin D/deficiency" \\
\hline "Prevalence" & "Mortality" \\
\hline
\end{tabular}

stimuli that increase production of vitamin D depend on blood calcium and phosphate levels. Hypocalcemia stimulates the secretion of parathyroid hormone (PTH), which in turn prompts the production of 1- $\alpha$-hydroxylase. A phosphate-poor diet also directly stimulates this enzyme. Moreover, 1- $\alpha$-hydroxylase is inhibited by high levels of blood calcium and a high concentration of both calcitriol (negative feedback) and fibroblast growth factor 23 (FGF23). These factors also contribute to the inhibition of calcitriol, stimulating 24-hydroxilase, which degrades both calcitriol and calcifediol.

FGF23 has an important role in the early pathogenesis of vitamin D deficiency in CKD. This phosphaturic hormone is secreted by osteocytes and osteoblasts to maintain phosphate homeostasis, especially in an early stage of kidney disease. FGF23 is regulated by its co-receptor, Klotho protein, which increases the affinity of the FGF23 to its receptor and regulates FGF23 synthesis [4].

Vitamin D receptor (VDR): The hormonal 1,25-dihydroxyvitamin $D_{3}\left(1,25(\mathrm{OH})_{2} \mathrm{D}_{3}\right)$ acts primarily through its union to the vitamin $\mathrm{D}$ receptor (VDR), a member of the nuclear hormone receptor family. In turn, $25(\mathrm{OH}) \mathrm{D}_{3}$ is also capable of binding to the VDR and activating it. Although its affinity is 200 times less, this is compensated for by a serum concentration 500 times higher (Table 2) [5].

VDR is a transcription factor, so the main action of 1,25-dihydroxyvitamin $D_{3}$ is to regulate gene expression in target tissues. Traditionally, these have been considered to be the small intestine, the bone, the kidneys, and the parathyroid glands. However, studies have also demonstrated the presence of both 1- $\alpha$-hydroxylase and VDR in the cells of other tissues, for example in the brain, heart, pancreas, vascular endothelium, and prostate, among other sites (Table $3)$. As a result, there is increasing knowledge on the effects derived from VDR activation [4].

In addition to vitamin D's well-known functions in regulating blood calcium as well as bone metabolism and mineralization, recent studies [4] point to a variety of other effects it has on different tissues. The activation of extraskeletal VDR participates in the regulation of the

\begin{tabular}{|l|c|c|c|c|}
\hline \multicolumn{2}{|c|}{ Table 2: Affinity to vitamin D receptor. *Relative values. } \\
& Affinity with VDR & $\begin{array}{c}\text { Total serum } \\
\text { concentration }\end{array}$ & Half-life & $\begin{array}{c}\text { Risk of } \\
\text { hypercalcemia }\end{array}$ \\
\hline $25(\mathrm{OH}) \mathrm{D}_{3}$ & $1^{*}$ & $9.0-34.0 \mathrm{ng} / \mathrm{mL}(500)^{*}$ & $480 \mathrm{~h}$ & Low \\
\hline $1,25(\mathrm{OH})_{2} \mathrm{D}_{3}$ & $100-200^{*}$ & $20-60 \mathrm{pg} / \mathrm{mL}$ & $15 \mathrm{~h}$ & High \\
\hline
\end{tabular}

Table 3: Cells with presence of vitamin D receptor (VDR).

\begin{tabular}{|c|c|}
\hline Table 3: Cells with presence of vitamin D receptor (VDR). \\
\hline Cells containing 1-a-hydroxylase and VDR \\
\hline Neurons & Renal tubular cells \\
\hline Dendritic cells & Enterocytes \\
\hline Macrophages & Vascular endothelial cells \\
\hline Lymphocytes T and B & Keratinocytes \\
\hline Osteoblasts and osteoclasts & Prostate cells \\
\hline Pancreatic cells & Colon cells \\
\hline
\end{tabular}


immune system and inflammation, the skeletal muscle, the energy metabolism, the cardiovascular system, and the modulation of cell proliferation. Some of the key functions of vitamin $\mathrm{D}$, of special importance in $\mathrm{CKD}$, include the reduction of inflammation and adipogenesis, maintenance of normal blood pressure, adequate insulin secretion, improvement of peripheral insulin resistance, regulation of cholesterol levels, and increase of vascular endothelial cell function.

Concept of sufficiency and prevalence of hypovitaminosis in the general population: The criteria to define optimal values of $25(\mathrm{OH}) \mathrm{D}_{3}$ are mainly based on the levels needed to obtain the maximum suppression of the PTH, to produce enough 1,25 vitamin D to ensure intestinal absorption of calcium, and to prevent clinical events related to its deficiency (fractures) [6]. Vitamin D deficiency is defined as levels of $25(\mathrm{OH}) \mathrm{D}_{3}$ of less than $20 \mathrm{ng} / \mathrm{mL}(50 \mathrm{nmol} / \mathrm{L})$, and insufficiency as levels of $20 \mathrm{ng} / \mathrm{mL}$ to $30 \mathrm{ng} / \mathrm{mL}$ in blood [6].

In a review ${ }^{7}$ of the prevalence of hypovitaminosis D in the general population of the United States, inadequate levels were detected in healthy children, young adults (especially African Americans), and the elderly. The prevalence of $25(\mathrm{OH}) \mathrm{D}_{3}$ levels under $20 \mathrm{ng} / \mathrm{mL}$ was approximately $36 \%$ in young adults aged 18 to 29 years, $41 \%$ in ambulatory patients aged 41 to 83 years, and up to $57 \%$ in hospitalized patients. The situation was similar in Europe, where the prevalence of deficiency was up to $30 \%$ in healthy adults and up to $70 \%$ in inpatients [8]. In patients with CKD, both insufficiency and deficiency of vitamin D may reach a prevalence of more than $80 \%$ [9]. It is noteworthy that the European Action on Nutrition and Health-Survey (EURONUT-SENECA) showed lower levels of vitamin D in Mediterranean countries (Italy, Greece, Spain), considered sunny countries, than in others like the Netherlands or Finland.

\section{Prognostic implications of vitamin D in CKD}

In the early stages of CKD, the production of calcitriol $\left(1,25\right.$ dihydroxyvitamin $\left.\mathrm{D}_{3}\right)$ slows down for various reasons: i) a decrease in the glomerular filtration rate (GFR), which in turn reduces the substrate for the conversion of the $25(\mathrm{OH}) \mathrm{D}_{3}$ to calcitriol; ii) a decrease in megalin expression; iii) the loss of 1 - $\alpha$-hydroxylase due to the structural renal commitment and the suppression of its activity, stemming from an increase in the FGF23 levels; and iv) the stimulation of the 24-hydroxylase enzyme. In more advanced stages of kidney disease, proteinuria begins to gain importance in vitamin D deficiency [10].

The already high prevalence of vitamin D deficiency rises even more as CKD progresses. In a Spanish cohort of patients with CKD not on dialysis [11], 51\% presented levels of 25 $(\mathrm{OH}) \mathrm{D}_{3}$ of less than $15 \mathrm{ng} / \mathrm{mL}$, while just $10 \%$ had levels above $30 \mathrm{ng} / \mathrm{mL}$. Calcitriol levels generally drop when the GFR is less than $60 \mathrm{~mL} / \mathrm{min}$, although low concentrations have been observed even when GFR is less than $80 \mathrm{~mL} / \mathrm{min}$
[12]. Initially, this decrease in calcitriol is probably due to the increase in FGF23; however, in advanced stages of CKD, hyperphosphatemia and the loss of renal mass are more important in reducing the synthesis of calcitriol [13].

Phosphate retention has been considered the initial trigger of the alterations associated with CKD. The tendency to retain phosphate contributes to hyperparathyroidism secondary to CKD, in part because of the decrease in both blood calcium and calcitriol synthesis. However, levels of serum phosphate are not elevated in most patients with early stage CKD, probably because of a reduction in the tubular reabsorption of phosphate mediated by PTH and FGF23. Levels of calcitriol, FGF23, and its co-receptor Klotho suffer alterations before PTH does (Figure 1).

FGF23, in the presence of Klotho, diminishes the synthesis of calcitriol by suppressing the activity of 1 - $\alpha$-hydroxylase and stimulating the 24-hydroxilase enzyme. FGF23 levels were measured in a cohort of $\mathrm{CKD}$, these levels were quite stable over time in most of the patients but in those with rising levels, where a higher risk of death was found. Moreover, higher FGF23 was independently associated with increased risk of death in multivariable-adjusted analyses of time-varying FGF23 [14]. In a 2017 cohort study of older people with CKD, Shardlow et al., analyzed elevated PTH, Vitamin D deficiency and elevated FGF23 levels as risk factors for all-cause mortality. They found vitamin D deficiency and elevated PTH were independent risk factors for all-cause mortality but elevated FGF23 was not [15].

Klotho increases the affinity of FGF23 to its receptor and regulates its synthesis, so that low levels of Klotho increase levels of FGF23. Moreover, emerging research is showing that Klotho is involved in multiple processes related to endothelial function, renal fibrosis, and cardiomyopathies. The production of Klotho is mainly renal, and its concentration decreases early in CKD, to the point that it could be considered an important biomarker in this entity. According to the latest research, Klotho may be a sensible biomarker for early diagnosis and a reliable prognostic indicator of renal progression and the development of cardiovascular diseases in CKD. However, more research is needed to assess this question [16].

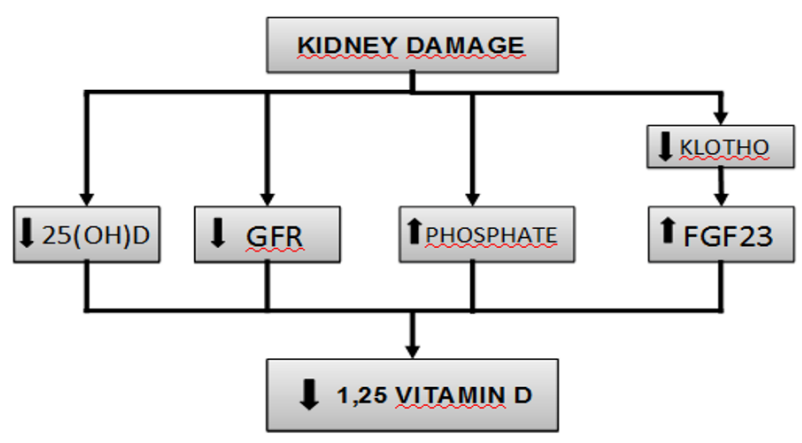

Figure 1: Pathogenesis of vitamin D deficiency in chronic kidney disease. 
Cardiovascular morbimortality in patients with CKD: The main cause of death in patients with CKD is by far cardiovascular disease [1]. It is known that CKD is a powerful predictor of adverse clinical outcomes and only a small minority of patients with CKD progress to the end stage renal disease with death prior to renal replacement therapy. Indeed, cardiovascular mortality is estimated to be up to $57 \%$ higher in patients with a GFR of less than $60 \mathrm{~mL} / \mathrm{min}$ compared to patients without CKD. The risk that these patients present a non-fatal myocardial infarction increases by $33 \%$ when the GFR is less than $60 \mathrm{~mL} / \mathrm{min}$ and by $48 \%$ in the presence of microalbuminuria. Moreover, for each $10 \mathrm{~mL} /$ min decrease in GFR, the risk of stroke increases by $7 \%$, or by $10 \%$ for each $25 \mathrm{mg} / \mathrm{mmol}$ increase in the albumin:creatine ratio[1,14,17,18] (Table 4). On the other hand, proteinuria is now widely accepted as an early indicator of renal injury that can be detected earlier than any tangible decline in GFR, as well as independent predictor of cardiovascular mortality and morbidity, addressing the role of proteinuria as a cardiovascular risk marker, and being evolved into a therapeutic target for cardiovascular risk reduction. An interesting review conducted by Currie and Delles [14], demonstrated the clear association between the presence of proteinuria and cardiovascular outcomes, not only in those with CKD, but in both diabetic and hypertensive patients, letting us consider proteinuria as a surrogate marker of cardiovascular risk.

Influence of vitamin $D$ in cardiac structure and function: Experimental data [19] suggest that vitamin D's intracellular pathways are involved in modifying cardiac structure and function. However, only limited evidence is available. In 2008, the PRIMO clinical trial assessed the effects of administering vitamin D (paricalcitol) in the mass of the left ventricle following 48 weeks of treatment in patients with CKD not on dialysis. The results were not statistically significant, showing no differences between the intervention and placebo groups. Later, in a post-hoc analysis, investigators observed that the vitamin D therapy reduced the levels of pro b-type natriuretic peptide as well as cardiovascular admissions (mainly due to congestive heart failure) in the group treated with paricalcitol. Based on this analysis, it seems that vitamin D has a role in cardiovascular function, although this would have to be demonstrated in future trials [19].

Association between vitamin D and endothelial function: Calcification and arterial rigidity are frequent findings in patients with CKD, and they influence cardiovascular mortality. Endothelial dysfunction can also be considered a factor in cardiovascular disease, and it appears to be associated with vitamin D deficiency. A cross-sectional study in 214 patients with CKD showed an independent association between low levels of $25(\mathrm{OH}) \mathrm{D}_{3}$ in blood and vascular calcification, as measured via radiodiagnosis [20]. Chitalia et al. [21], demonstrated that patients with CKD and vitamin D levels of $37.5 \mathrm{nmol} / \mathrm{L}(10.82 \mathrm{ng} / \mathrm{ml})$ or less show nearly twice the endothelial dysfunction (measured non-invasively using flow-mediated dilatation of the brachial artery) than those with higher levels.

Vitamin D levels affect survival in people with CKD, regardless of cardiovascular risk

A prospective cohort study [22] followed 140 patients with CKD at any stage for almost two years, studying the relationship between levels of vitamin D (25(OH)D in blood), vascular calcification, and mortality. Authors observed a significant association between low levels of serum $25(\mathrm{OH})$ D and mortality, independently of vascular calcification. Specifically, the study showed higher all-cause mortality rates in patients with $25(\mathrm{OH}) \mathrm{D}$ under the cutoff of $16.7 \mathrm{ng} / \mathrm{mL}$.

Levels of vitamin $D$ and progression of kidney disease: Animal models [23] suggest an important potential role for vitamin $\mathrm{D}$ in slowing the progression of kidney disease. These effects, through which vitamin D can theoretically protect renal structure and function, mainly consist of the suppression of the renin-angiotensin-aldosterone system, plus anti-inflammatory, antioxidant, and antiproliferative effects.

However, despite the plausible mechanisms through which vitamin D can exercise a protective renal effect, studies in humans are not entirely consistent. In a 2017 review, Mehrotra [23] analyzed the relationship between vitamin D and progression of kidney disease, as well as vitamin D's role in preventing and reducing proteinuria. The review concluded that low vitamin D is an important predictor of microalbuminuria, and treatment with vitamin $\mathrm{D}$ analogs has an anti-proteinuric effect. However, despite the association shown between increased proteinuria and CKD progression, there is no consensus about whether all anti-proteinuric therapies can slow the progression of kidney disease.

Thus, although numerous cohort studies have demonstrated that low levels of $25(\mathrm{OH}) \mathrm{D}_{3}$ in blood are consistently associated with reduced GFR and faster progression to dialysis, most of the clinical trials analyzed were unable to show any beneficial effect of vitamin D supplementation for delaying the progression of kidney disease. In fact, some of these studies even signaled that treatment with analogs was related to larger decreases in the filtration. It is still unclear whether vitamin D contributes to slowing CKD or if supplementation could be renoprotective in these patients. New clinical trials would be necessary to assess this hypothesis.

Vitamin D levels and mortality in patients with CKD: Vitamin D deficiency has been associated with cardiovascular risk and premature death in patients with CKD on hemodialysis. However, this association is not wellknown in the stages prior to dialysis. One cohort study [24] in more than 3000 patients not under dialysis in the United States observed a relationship between hypovitaminosis 
D and all-cause mortality. As levels of $25(\mathrm{OH}) \mathrm{D}_{3}$ decreased, the hazard ratio for all-cause death increased. Likewise, in another cohort study, Pietro Ravani et al. [25] analyzed the prognostic implication of vitamin D levels in patients with CKD not on dialysis, concluding that $25(\mathrm{OH}) \mathrm{D}_{3}$ of less than $15 \mathrm{ng} / \mathrm{mL}$ is predictive of a faster progression to dialysis and death. In a meta-analysis including patients with CKD, Stefan Pilz et al. [26], found that low levels of vitamin D were associated with higher mortality. These investigators included 10 studies involving 6800 patients, and the results showed a clear association between levels of $25(\mathrm{OH}) \mathrm{D}_{3}$ and mortality in patients with CKD. Analyzing vitamin D levels categorially ( $<10 \mathrm{ng} / \mathrm{mL}, 10 \mathrm{ng} / \mathrm{mL}$ to $20 \mathrm{ng} / \mathrm{mL}, 21 \mathrm{ng} / \mathrm{mL}$ to $30 \mathrm{ng} / \mathrm{mL}$, and $>30 \mathrm{ng} / \mathrm{mL}$ ), investigators found that for every $10 \mathrm{ng} / \mathrm{mL}$ increase in $25(\mathrm{OH}) \mathrm{D}_{3}$, mortality decreased by $14 \%$. Finally, Navaneethan et al. [27] found that $25(\mathrm{OH})$ $\mathrm{D}_{3}$ levels of less than $15 \mathrm{ng} / \mathrm{mL}$ increased the risk of all-cause mortality by as much as $33 \%$.

Vitamin D treatment for decreasing mortality and cardiovascular risk in CKD patients: Vitamin D supplementation rates has risen significantly among CKD patients during the last decade, and it has been associated with greater serum 25(OH)D levels. However, the effect on mortality remains unclear [28].

A review [29] showed that vitamin D therapies $(25(\mathrm{OH})$ $\mathrm{D}_{3^{\prime}}$, calcitriol, or synthetic derivatives) decreased mortality more than placebo or no intervention in patients with CKD. Patients not under dialysis and treated with vitamin D showed a risk of mortality of 0.73 (95\% confidence interval [CI] 0.57 to 0.98 ) compared to the control group, and cardiovascular death was about $37 \%$ lower (risk ratio [RR] 0.63, 95\% CI 0.44 to 0.92 ).

A meta-analysis [30] assessed treatment with different oral vitamin $\mathrm{D}$ analogs for reducing mortality and cardiovascular disease in patients with CKD. The 13 included studies, involving nearly 1500 patients, did not show a significant effect of treatment for all-cause (RR $0.84,95 \% \mathrm{CI}$ 0.47 to 1.52 ) or cardiovascular (RR $0.79,95 \% \mathrm{CI} 0.26$ to 2.28 ) mortality compared to the placebo group. The review authors concluded that there was insufficient evidence to show how vitamin D supplementation affected these patients.

However, in another meta-analysis [31], including 21 studies and 908 patients with CKD not on dialysis, paricalcitol (selective VDR activator) decreased the risk of cardiovascular events compared to the control group (RR 0.30, 95\% CI 0.16 to $0.56 ; \mathrm{p}<0.001$ ). Thus, although it seems clear that paricalcitol reduces the number of cardiovascular events in this population, more studies are needed that specifically aim to assess vitamin $\mathrm{D}$ treatment for reducing all-cause and cardiovascular mortality.

\section{Conclusion}

There is a considerable prevalence of hypovitaminosis
D in the general population. In people with CKD, vitamin D insufficiency and deficiency may reach a prevalence of more than $80 \%$. Vitamin D levels begin to fall in the early stages of CKD, even with GFRs of more than $60 \mathrm{~mL} / \mathrm{min}$.

CKD and its progression are associated with cardiovascular complications and high mortality. Vitamin D has an important prognostic role in CKD. Low levels are independently associated with greater all-cause mortality and especially with greater cardiovascular risk in patients with CKD not on dialysis.

Treatment with paricalcitol seems to reduce cardiovascular mortality - the primary cause of death in CKD; however, more trials are needed with the primary objective of relating vitamin D treatment to reduced mortality and of comparing different treatment options with vitamin D analogs.

\section{References}

1. Webster AC, Nagler EV, Morton RL, Masson P. Chronic Kidney Disease. Lancet. 2017; 389(10075): 1238-1252.

PubMed: https://www.ncbi.nlm.nih.gov/pubmed/27887750

2. Otero A, de Francisco A, Gayoso P, García F; EPIRCE Study Group. Prevalence of chronic renal disease in Spain: results of the EPIRCE study. Nefrologia. 2010; 30: 78-86. PubMed: https://www.ncbi.nlm.nih.gov/pubmed/20038967

3. Holick M. Vitamin D Deficiency. New England Journal of Medicine. 2007; 357: 266-281.

PubMed: https://www.ncbi.nlm.nih.gov/pubmed/17634462

4. LiuW,WuC,HungY,LiaoM,ShyuJ,LinYetal.Pleiotropiceffects ofvitamin D in chronic kidney disease. Clinica Chimica Acta. 2016; 453: 1-12. PubMed: https://www.ncbi.nlm.nih.gov/pubmed/26656443

5. Obi $\mathrm{Y}$, Hamano $\mathrm{T}$, Isaka $\mathrm{Y}$. Prevalence and prognostic implications of vitamin D deficiency in chronic kidney disease. Dis Markers. 2015; 2015: 868961.

PubMed: https://www.ncbi.nlm.nih.gov/pubmed/25883412

6. Bess Dawson-Hughes. 2018 Vitamin D deficiency in adults: Definition, clinical manifestations, and treatment. UpToDate [Internet]. 2019. http:///www-uptodate.com

7. Holick M. High Prevalence of Vitamin D Inadequacy and Implications for Health. Mayo Clinic Proc. 2006; 81: 353-373. PubMed: https:// www.ncbi.nlm.nih.gov/pubmed/16529140

8. Mithal A, Wahl D, Bonjour J, Burckhardt P, Dawson-Hughes B, et al. Global vitamin D status and determinants of hypovitaminosis D. Osteoporosis International. 2009; 20: 1807-1820. PubMed: https://www.ncbi.nlm.nih.gov/pubmed/19543765

9. Jordi B, Jesús E, Elvira FG. Vitamina $D$, receptor de la vitamina $D$ e importancia de su activación en el paciente con enfermedad renal crónica. Nefrología. 2015: 35: 1-12.

10. Dusso A, González E, Martin K. Vitamin D in chronic kidney disease. Best Practice \& Research Clinical Endocrinology \& Metabolism. 2011; 25: 647-655

PubMed: https://www.ncbi.nlm.nih.gov/pubmed/21872805

11. Yuste C, García De Vinuesa S, Goicoechea M. Deficiencia de vitamina $D$ en una cohorte española de pacientes con enfermedad renal crónica. Medicina Clínica. 2013; 141: 338-342.

12. Levin A, Bakris GL, Molitch M, Smulders M, Tian J, et al. Prevalence of 
abnormal serum vitamin D, PTH, calcium, and phosphorus in patients with chronic kidney disease: results of the study to evaluate early kidney disease. Kidney Int. 2007; 71: 31-38.

PubMed: https://www.ncbi.nlm.nih.gov/pubmed/17091124

13. Wajeh Y Qunibi, and William L Henrich, 2018. Overview of chronic kidney disease-mineral and bone disorder (CKD-MBD). [online] Uptodate.com 2019. http:///www-uptodate.com

14. Currie G, Delles C. Proteinuria and its relation to cardiovascular disease. Int J Nephrol Renovasc Dis. 2013; 7: 13-24. PubMed:

15. Shardlow A, Mclntyre NJ, Fluck RJ, Mclntyre CW, Taal MW, et al. Associations of fibroblast growth factor 23 , vitamin $D$ and parathyroid hormone with 5-year outcomes in a prospective primary care cohort of people with chronic kidney disease stage 3. BMJ Open. 2017; 7: e016528.

PubMed: https://www.ncbi.nlm.nih.gov/pubmed/28838895

16. Neyra JA, Hu MC. Potential application of klotho in human chronic kidney disease. Bone. 2017; 100: 41-49.

PubMed: https://www.ncbi.nlm.nih.gov/pubmed/28115282

17. Go AS, Chertow GM, Fan D, McCulloch CE, Hsu CY. Chronic kidney disease and the risks of death, cardiovascular events, and hospitalization. N Engl J Med. 2004; 351:1296-1305.

PubMed: https://www.ncbi.nlm.nih.gov/pubmed/15385656

18. Keith DS, Nichols GA, Gullion CM, Brown JB, Smith DH. Longitudinal follow-up and outcomes among a population with chronic kidney disease in a large managed care organization. Arch Intern Med. 2004; 164: 659-663.

PubMed: https://www.ncbi.nlm.nih.gov/pubmed/15037495

19. Thadhani $R$, Appelbaum E, Pritchett $Y$, Chang $Y$, Wenger J, et al. Vitamin $D$ therapy and cardiac structure and function in patients with chronic kidney disease: the PRIMO randomized controlled trial. JAMA. 2012; 307: 674-684. PubMed: https://www.ncbi.nlm.nih.gov/ pubmed/22337679

20. García-Canton C, Bosch E, Ramírez A, Gonzalez Y, Auyanet I, et al. Vascular calcification and 25-hydroxyvitamin $D$ levels in non-dialysis patients with chronic kidney disease stages 4 and 5 . Nephrol Dial Transplant. 2011; 26: 2250-2256.

PubMed: https://www.ncbi.nlm.nih.gov/pubmed/20956810

21. Chitalia N, Recio-Mayoral A, Kaski JC, Banerjee D. Vitamin D deficiency and endothelial dysfunction in non-dialysis chronic kidney disease patients. Atherosclerosis. 2012; 220: 265-268.

PubMed: https://www.ncbi.nlm.nih.gov/pubmed/22071357
22. Barreto DV, Barreto FC, Liabeuf $S$, Temmar $M$, Boitte $F$, et al. Vitamin D affects survival independently of vascular calcification in chronic kidney disease. Clin J Am Soc Nephrol. 2009; 4: 1128-1135. PubMed: https://www.ncbi.nlm.nih.gov/pubmed/19443628

23. Mehrotra R. Hypovitaminosis D and Progression of CKD. Chronic Kidney Disease in Disadvantaged Populations. 2017: 251-262.

24. Mehrotra R, Kermah DA, Salusky IB, Wolf MS, Thadhani RI, et al. Chronic kidney disease, hypovitaminosis $D$, and mortality in the United States. Kidney Int. 2009; 76: 977-983.

PubMed: https://www.ncbi.nlm.nih.gov/pubmed/19657329

25. Ravani P, Malberti F, Tripepi G, Pecchini P, Cutrupi S, et al. Vitamin $D$ levels and patient outcome in chronic kidney disease. Kidney Int. 2009; 75: 88-95.

PubMed: https://www.ncbi.nlm.nih.gov/pubmed/18843258

26. Pilz S, lodice S, Zittermann A, Grant WB, Gandini S. Vitamin D status and mortality risk in CKD: a meta-analysis of prospective studies. Am J Kidney Dis. 2011; 58: 374-382.

PubMed: https://www.ncbi.nlm.nih.gov/pubmed/21636193

27. Navaneethan SD, Schold JD, Arrigain S, Jolly SE, Jain A, et al. Low 25-hydroxyvitamin $D$ levels and mortality in non-dialysis-dependent CKD. Am J Kidney Dis. 2011; 58: 536-543.

PubMed: https://www.ncbi.nlm.nih.gov/pubmed/21816525

28. Mariani LH, White MT, Shults J, Anderson CA, Feldman $\mathrm{HI}$, et al. Increasing Use of Vitamin D Supplementation in the Chronic Renal Insufficiency Cohort Study. J Ren Nutr. 2014; 24: 186-193. PubMed: https://www.ncbi.nlm.nih.gov/pubmed/24613295

29. Duranton $F$, Rodriguez-Ortiz $M$, Duny $Y$, Rodriguez $M$, Daurès $J$, et al. Vitamin D Treatment and Mortality in Chronic Kidney Disease: A Systematic ReviewandMeta-Analysis. Am JNephrol.2013;37:239-248. PubMed: https://www.ncbi.nlm.nih.gov/pubmed/23467111

30. Mann MC, Hobbs AJ, Hemmelgarn BR, Roberts DJ, Ahmed SB, et al. Effect of oral vitamin D analogs on mortality and cardiovascular outcomes among adults with chronic kidney disease: a metaanalysis. Clin Kidney J. 2014; 8: 41-48.

PubMed: https://www.ncbi.nlm.nih.gov/pubmed/25713709

31. Hu X, Shang J, Yuan W, Zhang S, Jiang Y, et al. Effects of paricalcitol on cardiovascular outcomes and renal function in patients with chronic kidney disease: A meta-analysis. Herz. 2018; 43: 518-528. PubMed: https://www.ncbi.nlm.nih.gov/pubmed/28835982 